\title{
FIRST RESULTS FROM OEDOTENSIOMETRIC TESTS
}

\author{
Luigi Cavazza, Adriano Guarnieri, Antonia Patruno, Giulio Lorenzini, Elio Cirillo
}

\section{Introduction}

A general overview of the swelling soils [8] shows some aspects of using an oedotensiometer and the possibility of interpretation of its results. The main obstacles to the interpretation of the infiltration results using an oedontensiometer [7] is the uncertainty of the theoretical developments in the case of swelling soils. According to Philip [19] the mathematical complexity even in the case of homogeneous soil is far for showing the plainness that this author found for infiltration in rigid soils. On the other side, some uncertainty arise too in the description of the shrinkage curve (or swelling curve) for these soils $[25,11,23$, $14,15,4,6]$.

When it is considered the volumetric changes of a swelling soil related to the soil water content change, four domain are distinguished (fig. $1 \mathrm{a}$-b). If one starts from the maximum water content $\left(\theta_{\mathrm{gM}}\right.$ or $\vartheta_{\mathrm{M}}$; the symbol $\vartheta_{\mathrm{M}}$ shall be used later) of a volume of this soil and reduces in some way its water content, one could expect to obtain a soil volume contraction $(\Delta V$ soil) usually smaller than the volume of extracted water $\left(\Delta V_{\text {soil }}<\Delta w_{\text {vol }}\right)$; this means that he is dealing with the structural domain of the wetted soil. After further drying, the ratio between the soil volume contraction and the volume of water lost $\left(\Delta V_{\text {soil }} / \Delta w_{\text {vol }}\right)$ is expected to become constant (this ratio is usually 1 in the clay-paste tests); the soil is in its basic domain (which implies some small less porous volumes relatively dispersed in the structural domain frame); all pores involved in the basic domain remain water saturated

\section{Paper received 26.06.2007; accepted 21.10.2008}

Prof. L. CAVAzZA, Professore emerito Università di Bologna, già ordinario di Agronomia Generale, Dipartimento di Scienze e Tecnologie Agroambientali, DiSTA. Prof.ssa A. PATRUNO, già Professore associato di Fisica del Terreno Agrario, DiSTA, stessa Università. Prof. A. GUARNIERI, Professore ordinario Dipartimento Economia e Ingegneria Agrarie, DEIAGRA, stessa Università. Prof. G. LoRENZINI Professore associato di Idraulica Agraria e Forestale, DEIAGRA, stessa Università. Dott. E. Cirillo, Assegnista Post-Dottorato di Ricerca, DiSTA, stessa Università while the soil expresses its maximum relative swelling power; the water conductivity reduces appreciably when the moisture is passing from the structural to the basic domain. Under further drying the ratio soil volume to lost water volume again decreases due to air entry in the pores and this is the residual domain (usually not met in oedotensiometric tests). Many approximated schemata are known for this manifestation $[14,15,6]$.

When the process is reversed and it is considered the water infiltration in the soil column from below of the oedotensiometer, the advancing of wetting front is dependent upon the water pressure applied. Consider two contrasting cases:

a) if the water pressure applied is negative (similar to that of the infiltration through a depression disc permeameter), the advance of wetting front is very slow and only small soil pores are involved;

b) if the base of the soil column is in contact with water at rather high pressure, the water can easily and rapidly penetrate the larger empty pores of the structural domain, which, as first approximation, can be expected to have a random distribution. This means that in the earlier stages of infiltration, the water in the large pores moves so fast (faster the higher the inlet pressure) that some small volume of the basic domain can remain incompletely wetted behind. These small volumes having very low hydraulic conductivity can complete their wetting in a later time. These slow wetted volumes in the basic domain are also the most responsible for the swelling process.

If this pattern is correct after a suitable water inlet, it is expected an initial very high rate of water penetration in the sample, then a drop due to reduced water gradients, however followed by a delayed recover of water uptake by the dispersed volumes of the basic domain.

This description is essentially an Eulerian one. Due to non stationary conditions during the infiltration process, any attempt to a deeper analysis considering the use of Lagrangian transformations is inadequate. Most work on this subject, indeed, explicitly or implicitly assumes that motion in the aqueous phase and in the solid phase are simultaneous $[18,20,21,22$, 
10]. Some possibilities of analysis exist for the final swelling equilibrium when the saturation is reached in the whole sample especially if water feeding at the sample basis is not stopped and excess water accumulates on the sample top. The test consist in one-dimensional vertical infiltration of water.

\section{Materials and methods}

The oedotensiometer is fed from below by a solution of distilled and de-aerated water (containing $2 \%$ o boric acid) through a ceramic porous plate, which is water saturated throughout the test and have an hydraulic conductance per unit area $\left(L_{\text {pcer }}\right)$ of $1.230 \times 10^{-4}$
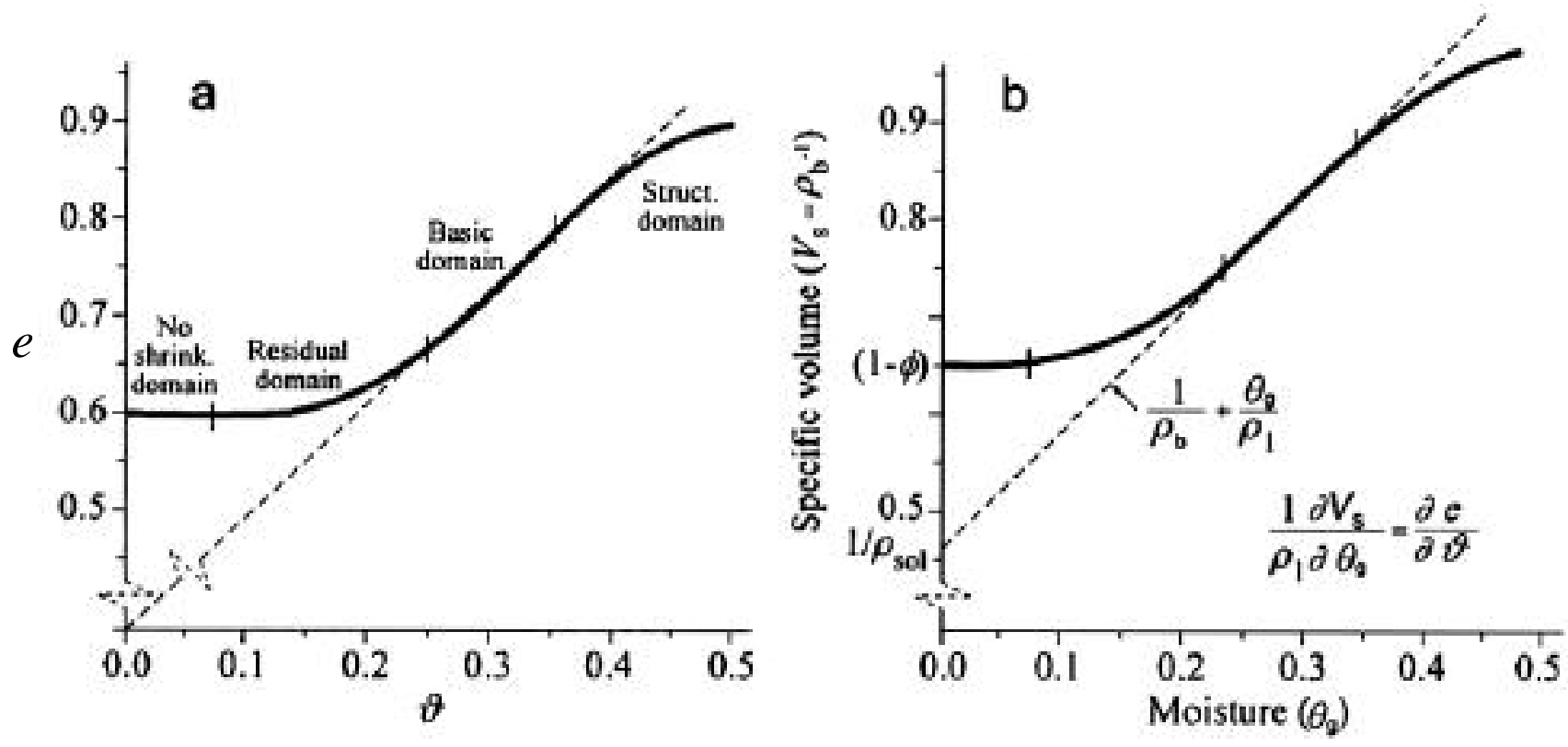

Fig. 1 - Schematic representation of the swelling-shrinking manifestation of a soil. Comparison between $e(\vartheta)$ and $V_{\mathrm{s}}\left(\theta_{\mathrm{g}}\right)$ representations; $V_{\mathrm{s}}$ means here "specific volume".
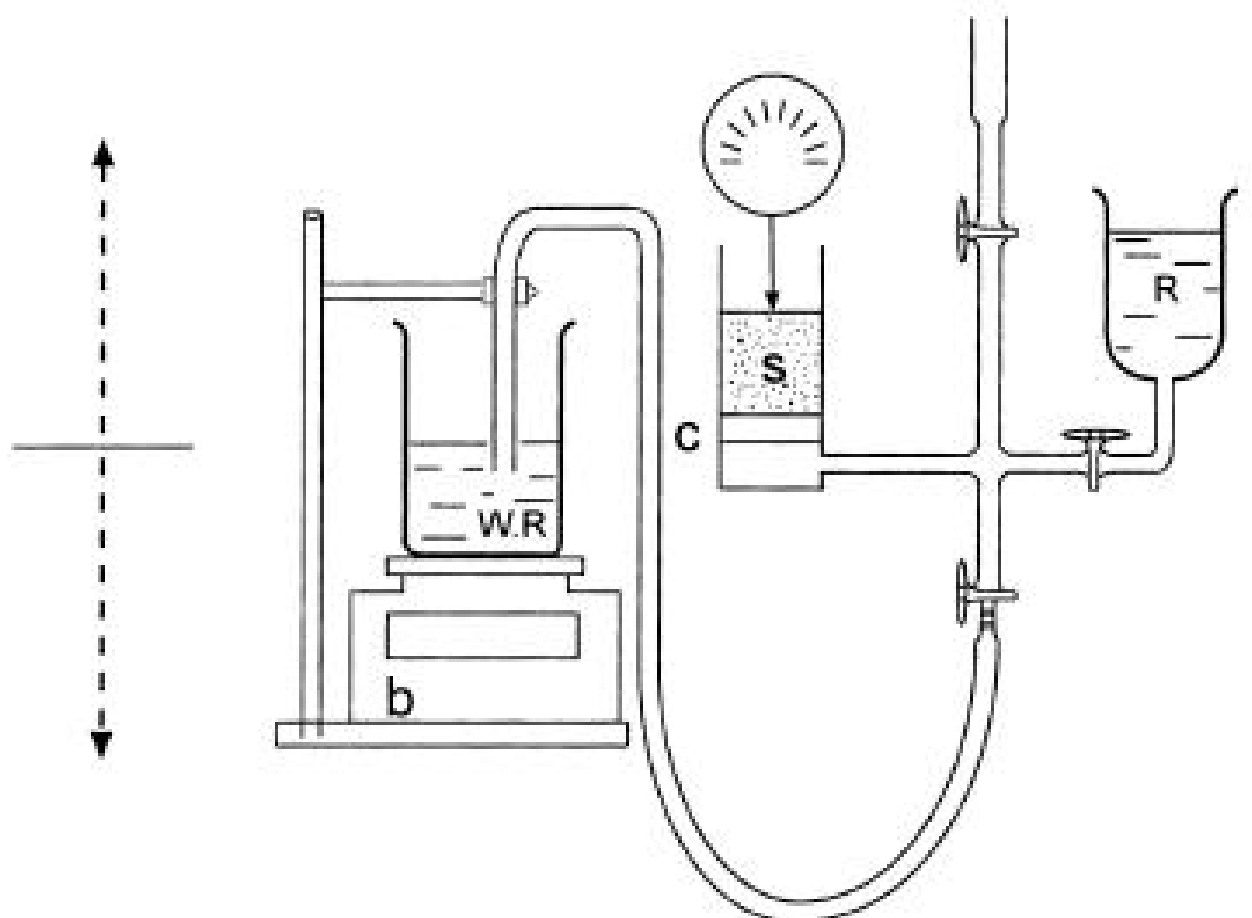

Fig. 2 - Outline of the oedotensiometer used: $\mathrm{s}=$ soil sample; $\mathrm{b}=$ balance; $\mathrm{WR}=$ water reservoir to be monitored; $\mathrm{R}=$ emergency reservoir; $\mathrm{C}=$ ceramic porous plate. The balance is moved up or down to regulate the pression at the ceramic. 
$\mathrm{s}^{-1(1)}$. An outline of the apparatus is shown in fig. 2 . The oedometric cell has maximum volume of 70.935 $\mathrm{cm}^{3}$ and basal area $\mathrm{A}=18.10 \mathrm{~cm}^{2}$. The water is fed to the plate at chosen hydraulic pressure that can be varied with continuity from positive to negative values.

When using a soil sample dry or near dry and if a low pressure (especially negative pressure) is applied at the ceramic plate the speed of the soil wetting is extremely low so that an adequate initially hydraulic head is preferred (e.g. $+10 \mathrm{~cm}$ of water). For draining saturated soil the water depression can be freely chosen.

For these tests a swelling soil with general field characteristic as given in table 1 is selected. The water retention curve of this soil was known. The soil taken from the $A p$ horizon was first air dried and then sieved under a $2 \mathrm{~mm}$ sieve. The solid density $\rho_{\mathrm{s}}$, in $\mathrm{kg} / \mathrm{m}^{3}$ was determined using water in the picnometer $[2,12]$. Before all tests hygroscopic water content, $\theta_{\mathrm{g}}$ in $\mathrm{kg} \mathrm{kg}^{-1}$, was measured and the amount of soil put in the oedometer cell was taken in all cases $42 \mathrm{~g}$ of dry soil [13]. This was compressed to the desired degree by dropping a falling load like in the case of a Proctor test reaching the density given in table 2 .

In most figures the water entered in the soil sample and the swelling of this were expressed as moisture ratio $(\vartheta)$ and void ratio of the sample $(e)$.

In these type of tests the rate of the water uptake, as well as that of the water drainage were not imposed. They were the consequences of the experimental conditions; data in the last column of table 2 and 3 often include rest periods between intervals of observation.

Beside of the tests on the soil taken from the field a number of tests were performed on the same soil treated in such a way as to simulate damages from a rather high degree of sodication and salinization like those determined by long period of bad agronomic practice using sodic saline water for irrigation [17]. To this purpose a certain amount of soil from the same field of Baricella was immerged in a $100 \mathrm{mM}$ solution and SAR 45, obtained by dissolving Na-acetate and $\mathrm{Ca}$-acetate buffered to $\mathrm{pH} 9.33$ through the addition of sodium hydroxide. After a bath of $24 \mathrm{~h}$ and drainage of $4 \mathrm{~h}$ the soil was partially dried in oven at $40{ }^{\circ} \mathrm{C}$. This treatment was repeated on the same material 3 to 5 times to forward the ionic ex-

(1) To evaluate the conductance per unit area of the plate (thickness $0.007 \mathrm{~m}$ ), a blank test was previously performed applying a differential feeding pressure of $+10 \mathrm{~cm}$ of water. The equation obtained in these conditions was:

$\left(\mathrm{d} V_{2} / \mathrm{d} t\right)+\left(1+d_{1}^{2} / d_{2}^{2}\right) L_{\mathrm{pcer}} V_{2}=+L_{\mathrm{pcer}} V_{\Sigma}$

where $V_{2}$ is the water content in the feeding tank; $V_{\Sigma}$ is the total water in both reservoirs (constant); $d_{1}$ and $d_{2}$ are the diameter of releasing and receiving tanks; $L_{\mathrm{pcer}}$ is the unknown conductance of the plate per unit area. The model to solve this non homogenous linear differential equation of $1^{\text {st }}$ order was taken by Apostol [1] being in our case $P$ and $Q$ in Apostol formula fixed values. The hydraulic conductance per unit area of the plate was $L_{\mathrm{per}}=1.23 \times 10^{-4} \mathrm{~s}^{-1}$; for a plate thickness of 0.007 $\mathrm{m}$; then $K_{\text {cer }}=8,61 \times 10^{-7} \mathrm{~m} \mathrm{~s}^{-1}$.

\begin{tabular}{|c|c|c|}
\hline \multicolumn{2}{|l|}{ Location } & Baricella \\
\hline \multirow{2}{*}{\multicolumn{2}{|c|}{ Soil type [27] }} & Ustic \\
\hline & & Endoaquerts \\
\hline \multicolumn{2}{|l|}{ Soil series [3] } & Risaia del duca \\
\hline \multicolumn{2}{|l|}{ Sand $(2-0.05 \mathrm{~mm})$} & 0.15 \\
\hline \multicolumn{2}{|c|}{ Sand $(0.05-0.02 \mathrm{~mm}) \quad \%$ d.m. } & 0.37 \\
\hline \multicolumn{2}{|c|}{ Silt $(0.02-0.002 \mathrm{~mm}) \quad \%$ d.m. } & 26.64 \\
\hline \multicolumn{2}{|l|}{ Clay $(<0.002 \mathrm{~mm})$} & 72.84 \\
\hline \multicolumn{2}{|l|}{ Organic matter } & 3.18 \\
\hline \multicolumn{2}{|c|}{ Carbonates $\quad \%$ d.m. } & 13.00 \\
\hline \multicolumn{2}{|l|}{$\mathrm{pH}(1: 5)$} & 8.2 \\
\hline \multicolumn{2}{|r|}{$\left(\mathrm{mM}_{\mathrm{c}} \mathrm{kg}^{-1}\right)$} & 315 \\
\hline \multicolumn{3}{|l|}{ Clay minerals } \\
\hline \multicolumn{3}{|l|}{ Illite } \\
\hline Chlorite & [\% clay $]$ & 6.00 \\
\hline Kaolinite & [\% clay] & 9.00 \\
\hline \multicolumn{2}{|c|}{ Expandable clay [\% clay] } & 31.00 \\
\hline Specific surface & $(\mathrm{EGME})^{*}$ & 180 \\
\hline ESP & $(\% \mathrm{CEC})$ & 0.54 \\
\hline $\mathrm{EC}$ & $\left(\mathrm{m} \mathrm{S}^{-1}\right)$ & 93 \\
\hline \multicolumn{3}{|c|}{ Water retention curve (summer) } \\
\hline$\theta_{\mathrm{g}}$ at $10 \mathrm{kPa}$ & (\% d.m.) & 38.63 \\
\hline$\theta_{\mathrm{g}}$ at $33 \mathrm{kPa}$ & (\% d.m.) & 36.83 \\
\hline$\theta_{\mathrm{g}}$ at $1500 \mathrm{kPa}$ & (\% d.m.) & 27.79 \\
\hline$\rho_{\mathrm{s}}$ (on solids in water) & $\left(\mathrm{kg} \mathrm{m}^{-3}\right)$ & 2750 \\
\hline
\end{tabular}

* EGME : ethylene glycol mono-ethyl ether; determined by Professor Antonio Violante to whom the Authors are grateful.

TABLE 1 - Main feature of the soil and some sodicating treatment. Material sieved under $2 \mathrm{~mm}$.

change against the resistance to the ionic diffusion (one treatment alone had negligible effects); after the last bath the material was definitively dried (at $40^{\circ} \mathrm{C}$ ), crushed and sieved. This bathing process did not complete the ionic exchange. ESP reached and the salinity $\mathrm{EC}$, in $\mu \mathrm{S} \mathrm{m}^{-1}$ of the final material are shown in table 2. Some features of all these soils are summarized in table 2 and 3.

For the tests with the oedotensiometer the measurement of the water entry was monitored using a balance with a precision of $0.1 \mathrm{~g}$; for the swelling of the sample a space transducer was used with precision of $0.01 \mathrm{~mm}$ placed at the centre of a perspex perforated plate covering the top of the soil sample. Air was free to escape from the sample during the tests.

For a given water pressure applied at the inlet ceramic plate, the rate of the water entry $v(t)$ changed with time $t$. The volume of water $(V)$ entered at time $t$ is given by:

$$
V(t)=A \int_{0}^{\mathrm{t}} \mathrm{V} \cdot \mathrm{d} t
$$

and implies a corresponding mean moisture $\bar{e}_{\mathrm{g}}$ (non 
indicated) of the swelling sample (as gravitational water content for $\rho_{1}=1$ ).

This volume $V$ was expressed in most figures of this text as moisture ratio $(\vartheta)$ of the sample in which the water entered ${ }^{(2)}$. One could not know the distribution of this water inside the sample at different time nor the swelling answer of the soil

at different time $t$ and different height $z$ along the sample due to the transient conditions. The final state of water saturation (apparent as in all similar cases) and of corresponding swelling were measured (the swelling effect was expressed in this text as void ratio $e)$. In some cases the entry of water was let to follow after the water appeared at the top of the sample and the evolution of the water flux and the soil swelling were monitored. As a rule a succession of a wetting and a draining process was applied.

\section{Results and discussion. The wetting process; untreated soil}

Starting from hygroscopic moisture the rate of the uptake of water in the untreated soil sample (fig. 3a) shows an initial sharp increase and slowly declines towards the sample saturation (evaluated at saturation $S$ $=1.02 \%$ ). In the second (fig. 3b) and third wetting (Group I, tab. 2) the soil started from wet conditions and the water uptake was slower. Only a modest effect of soil settling appeared when comparing the $e$ of the $1^{\text {st }}$ to the next maximum swelling.

Almost parallel to the water uptake the sample started swelling (fig. 4a). The maximum swelling at the end of the $1^{\text {st }}$ wetting was about $12 \%$ of the initial volume.

More evident is the evolution of the water uptake when its derivative with respect to the time is considered (fig. 3 a'-b'). In the first wetting, after a rapid initial decline the curve of the water uptake deviates from the expected asymptotic reduction (hypothesized dotted line) showing a relative increase of water uptake which supports the pattern exposed in the previous paragraph (the delayed swelling in basic domain). As expected this effect disappears in the $2^{\text {nd }}$ (fig. 3b') and $3^{\text {rd }}$ wetting (Group I, tab. 2).

The swelling is expected to increase more or less asymptotically (fig. 4). The rate of swelling (= derivative of the sample height; fig. 4a') shows an analogous variation though more irregular due to the less precise measurements of the sample height. More convincing seems the ratio between the derivative of the sample height with respect to time, to the derivative of the water uptake with respect to the time (fig. $5 b)$. Though irregularly it appears that after about 25

\footnotetext{
(2) Remember that in our case: $e(t)=\left(\rho_{\mathrm{s}} / \rho_{\mathrm{b}(\mathrm{t})}\right)-1$; $\vartheta=\theta_{\mathrm{v}}(1-\ddot{O}) ; \theta_{\mathrm{v}}=\theta_{\mathrm{g}}\left(\rho_{\mathrm{b}} / \rho_{\mathrm{l}}\right)$
}

min there is a prevailing height expansion over the water uptake.

All these results demonstrate that in the test considered, there are two process which are not simultaneous and suggest the validity of the general pattern previously illustrated; i.e. the possible difference behaviour between the small volumes composing the basic domain and the remaining structural material.

This results notably complicate the process of the motion of aqueous and solid phases as has been assumed by most Authors [20, 21, 22, 26, 10] dealing with simultaneous flow of liquid and solutes in swelling soils. Then their techniques and conclusions could not be applied to our problems. Consider however that when trying to introduce the material (or Lagrangian or referential) coordinate $(\mathrm{m})$, the volume concentration of solid matter $\left(\theta_{\mathrm{s}}=\rho_{\mathrm{b}} / \rho_{\mathrm{s}}\right.$, where $\mathrm{s}$ mean solids), would imply that for homogenous material and simultaneous processes one should expect to have :

$$
\mathrm{dm} / \mathrm{dz}=1 /(1+e)=V_{\mathrm{s}} / V_{\Sigma}=\rho_{\mathrm{b}} / \rho_{\mathrm{s}}=\theta_{\mathrm{s}}
$$

where $V$ s means here value of solids.

With our data, instead, it is only possible to evaluate a mean $\bar{e}_{\mathrm{s}}$ for the whole sample at any given mean water content $\bar{e}_{\mathrm{g}}$ (fig. 6). This consideration shall be reviewed later. It would require much extensive measurement to understand what happens inside the sample and for distinct domains.

\section{Hydraulic conductivity of swollen soils}

Consider now the case in which, after the complete saturation of the sample, some water was left accumulate on the top of the sample. The first observation was that while the water accumulated the soil still followed for a certain time to swell somewhat; this is only the consequence of the previously noted delay in soil swelling. This process (table 4) stopped after a short time and implied a further increase of $0.58 \%$ of the final sample height. The water inlet was then stopped. Because this increase was negligible, for further determinations this final delayed swelling was neglected when calculating an approximate evaluation of the soil hydraulic conductivity. This was done after taking a) the final soil sample height as measured; b) the amount of water accumulated during this waterlogging time; c) the hydraulic head determining this flux. This head was taken as the height of the accumulated water on the sample, plus the sample height, plus the difference of the feeding potential at the porous plate bottom $(+10 \mathrm{~cm})$, minus the loss of hydraulic head due to the conductance of the porous plate (details in appendix). For the conductance of the porous plate see note ${ }^{(1)}$. The results is that the $K_{\mathrm{s}}$ value for the saturated sample was about $3.20 \times 10^{-8} \mathrm{~m} \mathrm{~s}^{-1}$. 


\begin{tabular}{|c|c|c|c|c|c|c|c|c|c|c|c|c|c|c|c|}
\hline \multirow{2}{*}{$\begin{array}{c}\text { Infiltration } \\
\text { tests }\end{array}$} & \multicolumn{5}{|c|}{ Initial soil conditions } & \multirow{2}{*}{$\begin{array}{l}\text { Feeding } \\
\text { water } \\
\text { potential } \\
(\mathrm{cm} \text { of } \\
\text { water }^{(1)}\end{array}$} & \multicolumn{3}{|c|}{ Moisture (w) } & \multirow{2}{*}{$\begin{array}{c}\text { Calculated } \\
\text { Final } \\
\text { Saturation } \\
(\vartheta \text { as } \% e)\end{array}$} & \multirow{2}{*}{$\begin{array}{c}\text { Mechan. } \\
\text { load } \\
(\mathrm{kPa})\end{array}$} & \multicolumn{3}{|c|}{ Soil swelling } & \multirow{2}{*}{$\begin{array}{c}\text { Rough } \\
\text { time } \\
\text { Infiltrat. } \\
\text { (min) }\end{array}$} \\
\hline & $\begin{array}{l}\text { Height of } \\
\text { column } \\
(\mathrm{mm})\end{array}$ & $\begin{array}{c}\rho_{\mathrm{b}} \\
\mathrm{Mkg} \mathrm{m}^{-3}\end{array}$ & $\begin{array}{c}\mathrm{ESP} \% \\
\mathrm{CEC}\end{array}$ & $\begin{array}{c}\mathrm{EC} \\
\mu \mathrm{S} \mathrm{m}^{-1} \\
(1: 5)\end{array}$ & $\begin{array}{l}\text { Hygr. } \\
\text { water }\end{array}$ & & Initial & Final & $\begin{array}{l}\text { Diff. (\% } \\
\text { of init.) }\end{array}$ & & & $\begin{array}{l}\text { Initial } \\
\text { state } \\
(\mathrm{mm})\end{array}$ & $\begin{array}{l}\text { Final } \\
\text { state } \\
(>\max )\end{array}$ & $\begin{array}{c}\% \text { of } \\
\text { initial }\end{array}$ & \\
\hline \multicolumn{16}{|l|}{ Group I } \\
\hline $1^{\text {st }}$ wetting & 21.57 & 1.076 & 0.54 & 93 & 0.0455 & +10 & 0.0455 & 0.6829 & 1400.8 & 101.1 & & 21.57 & 24.13 & +11.9 & 150 \\
\hline $2^{\text {nd }} \quad "$ & & $"$ & $"$ & $"$ & $"$ & +10 & 0.4081 & 0.6607 & 61.9 & 98.8 & & 23.78 & 23.96 & +0.75 & 1200 \\
\hline $3^{\text {rd }} \quad "$ & & $"$ & $"$ & $"$ & $"$ & +10 & 0.4178 & 0.6550 & 56.8 & 98.2 & & 23.79 & 23.91 & +0.50 & 270 \\
\hline $4^{\text {th }} \quad "$ & & $"$ & $"$ & $"$ & $"$ & +10 & 0.4460 & 0.6412 & 43.8 & 97.1 & 0.596 & 23.80 & 23.78 & -0.084 & 190 \\
\hline $5^{\text {th }} \quad "$ & & $"$ & $"$ & $"$ & $"$ & -18 & 0.4557 & 0.5309 & 16.5 & 81.4 & 0.596 & 23.60 & 23.59 & -0.002 & 1270 \\
\hline \multicolumn{16}{|l|}{ Group II } \\
\hline $1^{\text {st }}$ wetting & 21.52 & 1.079 & 24.66 & 1410 & 0.0383 & +10 & 0.0385 & 0.8057 & 1992.7 & 103.9 & & 21.52 & 25.46 & +23.10 & 1830 \\
\hline $2^{\text {nd }} \quad "$ & & $"$ & $"$ & $"$ & $"$ & +10 & 0.5379 & 0.8371 & 55.6 & 113.0 & & 25.23 & 25.65 & +1.66 & 95 \\
\hline $3^{\text {rd }} \quad "$ & & $"$ & $"$ & $"$ & $"$ & +10 & 0.5681 & 0.7971 & 40.3 & 112.9 & & 25.36 & 26.21 & +3.35 & 130 \\
\hline $4^{\text {th }} \quad "$ & & $"$ & $"$ & $"$ & $"$ & -18 & 0.6240 & 0.6348 & 1.7 & 104.2 & 0.596 & 25.54 & 25.35 & -0.74 & 130 \\
\hline \multicolumn{16}{|l|}{ Group III } \\
\hline $1^{\text {st }}$ wetting & 21.44 & 1.083 & 41.45 & 515 & 0.0479 & +10 & 0.0479 & 0.8681 & 1712.3 & 103.0 & & 21.44 & 27.84 & +29.9 & 5826 \\
\hline
\end{tabular}

(1) At the bottom of the ceramic plate

TABLE 2 - General features of single water infiltration tests. 

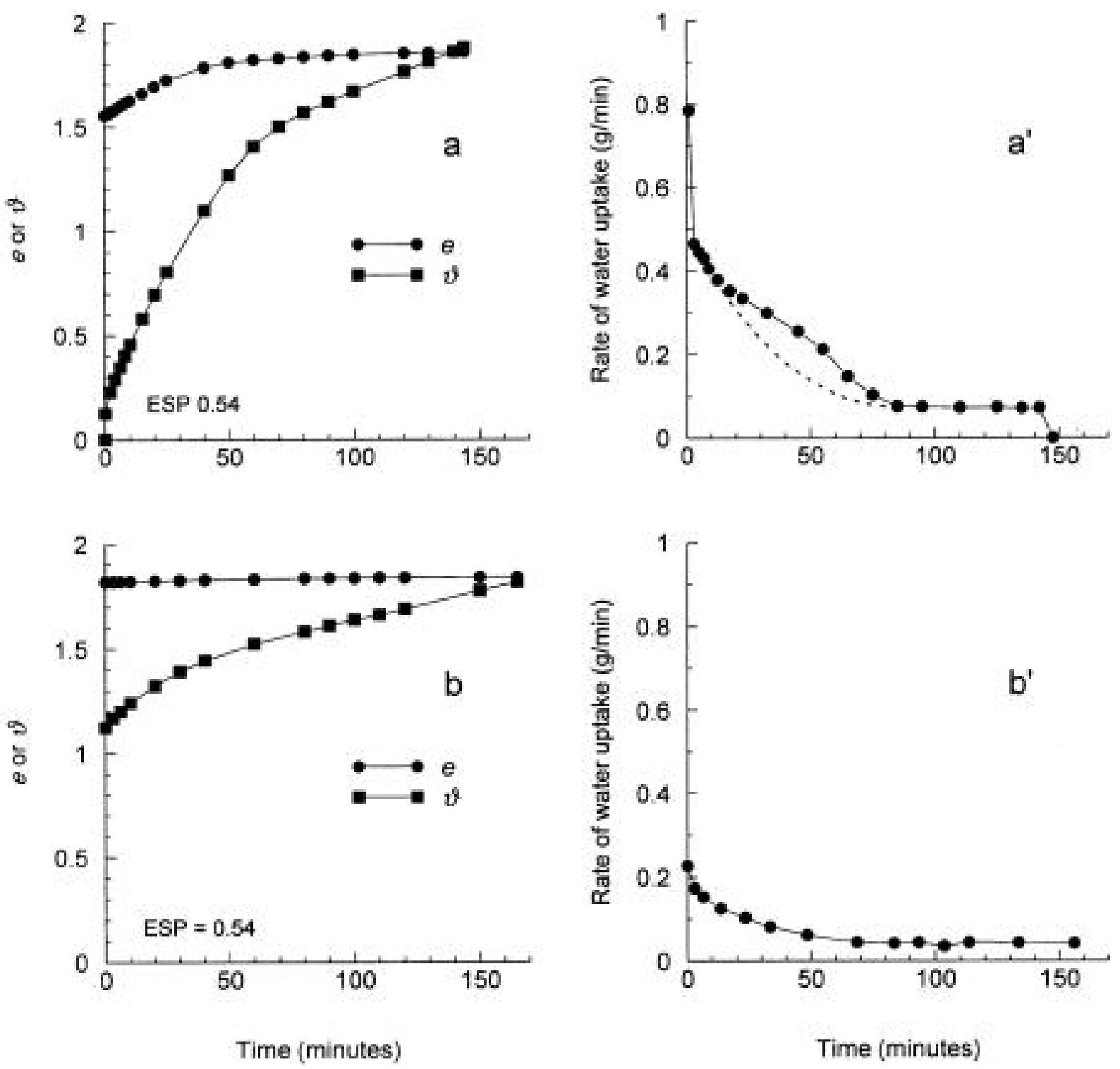

Fig. 3 - a) Variation of the moisture ratio $(\vartheta)$ and the void ratio $(e)$ in untreated soil sample (ESP of soil: $0.54 \%)$ during the wetting process in the first run. b) the same in the second run. a') rate of variation in time of the data in section a (derivative $\partial \vartheta / \partial t$ and $\partial e / \partial t(t$ in min); dotted line means expected asymptotically decrease). b') as in section a' for the second run.

\section{Sodicated soils}

Let us now consider the sodicated soils (figures 45). As consequence of the soil dispersion due to the sodication treatment there is an increase of the water content at the end of the wetting process; this is not proportional to the ESP value (tab. 2). This could possibly due to the fact that at different increases of ESP (II and III Group in tab. 2) correspond to different values of the salinity (EC) the action of which tends to partially counterbalance the dispersive effect of ESP. The limited number of treated soils (n. 3), gives only the possibility to approximately express in numerical terms the contribution to the maximum final water content given by the said factors. The solution of a tree equations system gives a weight of $-4.78 \times 10^{-3}$ for the ESP and $2.41 \times 10^{-5}$ for the EC (be- ing the constant term equal to 0.6618). The prevailing negative effect of ESP is evident.

Figure $4 \mathrm{a}$ (left) shows the swelling as a function of time for the three ESP samples. This confirm the sodication effect on swelling and shows the strong increase in time that this swelling implies. Figure 4a' (right) shows the derivative of the sample height as function of time and evidences the effect of delayed swelling of the basic domain in the untreated soil.

Figure 5 (right) express the ratio between the rate of the swelling and the rate of water intake (fig. $5 \mathrm{~b}$-cd). In the untreated soil (fig. 5b) the delayed swelling is still more evident that in fig. 4a'. This ratio is however very irregular and implies longer times when the soil is sodicated (fig. 5 c-d).

In the case of the soil with ESP 24.66 the rate of water intake decreased when passing from the $1^{\text {st }}$ to 

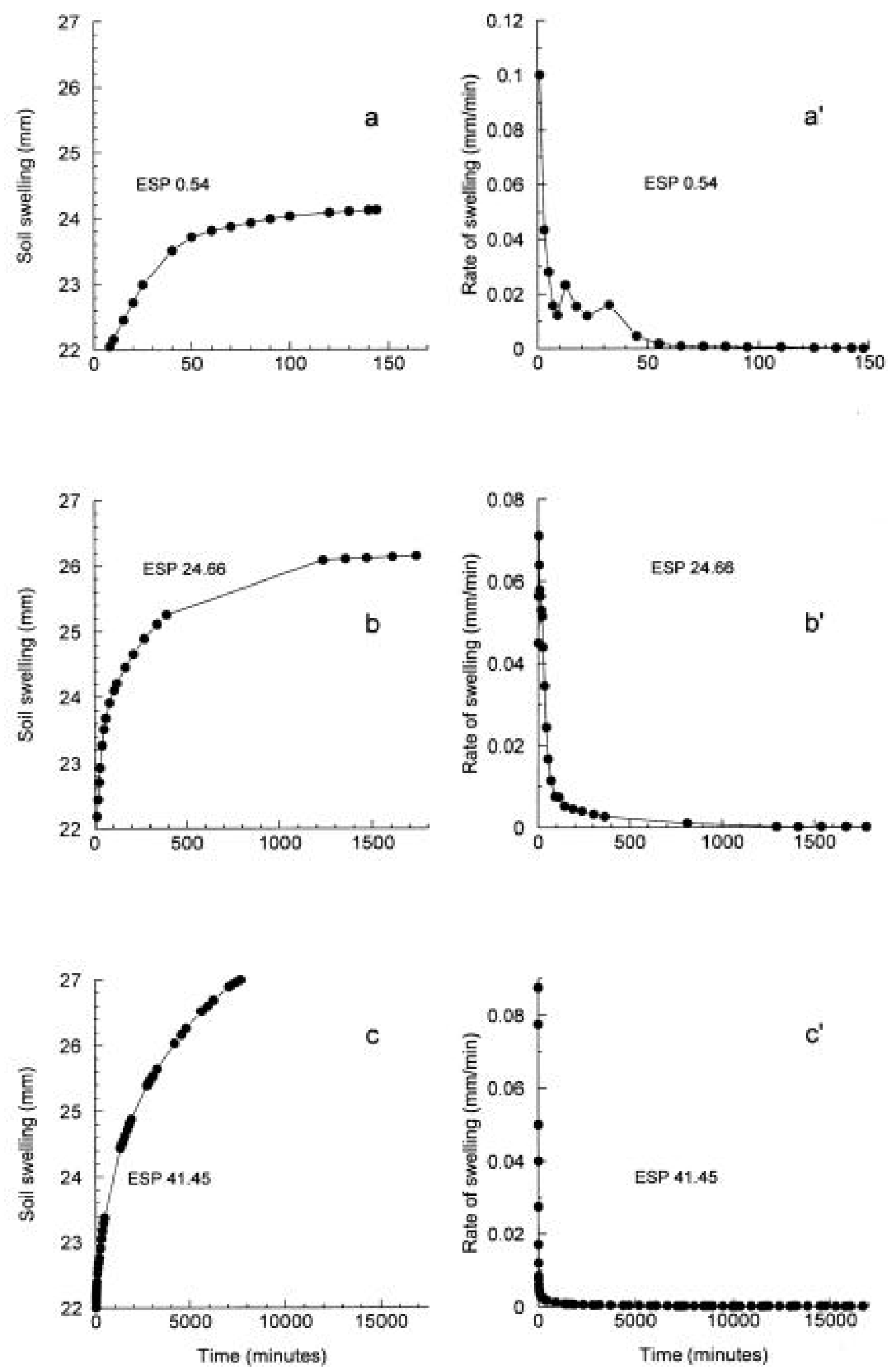

Fig. 4 - a) Soil swelling (height in $\mathrm{mm}$ ) as function of time for untreated soil (ESP $0.54 \%$ corresponding to moisture variation in fig. $3 \mathrm{a}$; b) as in a) for soil sodicated with ESP $24.66 \%$.c) as in a) for soil sodicated with ESP $41.45 \%$; a') rate of swelling as a function of time for untreated soil (ESP $0.54 \%$ ); b') as in a' for soil sodicated with ESP $24.66 \%$; c') for soil sodicated with ESP $41.45 \%$. 


\begin{tabular}{|c|c|c|c|c|c|c|c|c|c|c|}
\hline \multirow{2}{*}{$\begin{array}{c}\text { Outflow } \\
\text { tests }\end{array}$} & \multirow{2}{*}{$\begin{array}{c}\text { Initial soil } \\
\text { ESP } \\
(\% \text { CEC })\end{array}$} & \multirow{2}{*}{$\begin{array}{l}\text { Suction } \\
\text { potential } \\
\text { at the } \\
\text { ceramic } \\
\text { plate } \\
\text { (cm of } \\
\text { water) }\end{array}$} & \multicolumn{3}{|c|}{ Moisture $(w)$} & \multirow{2}{*}{$\begin{array}{c}\text { Mechan. } \\
\text { load } \\
(\mathrm{kPa})\end{array}$} & \multicolumn{3}{|c|}{ Soil shrinking } & \multirow{2}{*}{$\begin{array}{c}\text { Rough } \\
\text { time } \\
\text { for } \\
\text { outlet } \\
\text { test } \\
\text { (min) }\end{array}$} \\
\hline & & & Initial & Final & $\begin{array}{l}\text { Diff. } \\
\text { (\% of } \\
\text { init.) }\end{array}$ & & $\begin{array}{c}\text { Initial } \\
\text { state } \\
(\mathrm{mm})\end{array}$ & $\begin{array}{c}\text { Minimum } \\
\text { reached } \\
(\mathrm{mm})\end{array}$ & $\begin{array}{c}\% \text { of } \\
\text { initial }\end{array}$ & \\
\hline \multicolumn{11}{|l|}{ Group. I } \\
\hline $1^{\mathrm{st}}$ & 0.54 & -112 & 0.6414 & 0.4026 & -37.2 & & 24.12 & 23.80 & -1.33 & 248 \\
\hline $2^{\text {nd }}$ & “ & -112 & 0.6807 & 0.4152 & -39.0 & & 23.96 & 23.83 & -0.54 & 380 \\
\hline $3^{\text {rd }}$ & “ & -112 & 0.6207 & 0.4269 & -31.2 & & 23.91 & 23.80 & -0.46 & 1190 \\
\hline $4^{\text {th }}$ & “ & -112 & 0.6050 & 0.4512 & -25.4 & 0.596 & 23.78 & 23.60 & -0.76 & 1125 \\
\hline \multicolumn{11}{|l|}{ Group. II } \\
\hline $1^{\mathrm{st}}$ & 24.66 & -112 & 0.8057 & 0.5379 & -33.2 & & 26.46 & 25.23 & -4.65 & 1510 \\
\hline $2^{\text {nd }}$ & “ & -112 & 0.8371 & 0.5681 & -32.1 & & 25.65 & 25.36 & -1.13 & 1204 \\
\hline $3^{\text {rd }}$ & “ & -112 & 0.7660 & 0.6240 & -18.5 & & 26.21 & 25.54 & -2.56 & 1309 \\
\hline \multicolumn{11}{|l|}{ Group. III } \\
\hline $1^{\mathrm{st}}$ & 41.45 & -112 & 0.8681 & 0.7317 & -15.7 & & 27.84 & 24.98 & -10.27 & 5826 \\
\hline
\end{tabular}

TABLE 3 - General features of single water outflow tests.

the $2^{\text {nd }}$ and the $3^{\text {rd }}$ wetting. When the rate of water intake was normalized (dividing by the initial intake value of each wetting) one could obtain the graph of fig. 5a which shows that in the $1^{\text {st }}$ wetting this derivative shows a negligible effect of the delayed water adsorption compared to the one of fig. $5 b$; however this

\begin{tabular}{|lc} 
Duration of waterlogging $(\mathrm{s})$ & 3780 \\
Max volume accumulated $\left(\mathrm{m}^{3}\right)$ & $3.97 \times 10^{-6}$ \\
Max height over sample surface $(\mathrm{m})$ & $2.193 \times 10^{-3}$ \\
$\begin{array}{l}\text { Sample height at hygroscopic } \theta_{\mathrm{g}}(\mathrm{m}) \\
\begin{array}{l}\text { Sample height at beginning waterlogging } \\
(\mathrm{m})\end{array}\end{array}$ & $21.157 \times 10^{-3}$ \\
$\begin{array}{l}\text { Sample height at complete solid swelling } \\
(\mathrm{m})\end{array}$ & $24.13 \times 10^{-3}$ \\
$\begin{array}{l}\text { Increase during waterlogging }(\mathrm{m}) \\
\text { Relative increase during waterlogging } \\
(\% \text { tot. incr.) }\end{array}$ & $0.10 \times 10^{-3}$ \\
$\begin{array}{l}\text { Total swelling since the begin. }(\mathrm{m}) \\
\text { Relative incr. since the beginning } \\
(\% \text { initial) }\end{array}$ & $2.56 \times 10^{-3}$ \\
\end{tabular}

TABLE 4 - Data for the evaluation of the hydraulic conductivity $K_{\mathrm{s}}$ of submerged untreated soil ( $1^{\text {st }}$ wetting; see appendix). effect becomes more evident in the $3^{\text {rd }}$ wetting where it is similar to the one noted in the $1^{\text {st }}$ wetting of the untreated soil (fig. 3a'). This suggests that each cycle of wetting and drying could imply a certain rinsing of the salts in the pore space of the soil, making this more and more similar to that of the untreated soil.

The dispersing effect of sodication seems to make the soil less permeable (longer time in fig. 5 from $5 \mathrm{~b}$ to $5 \mathrm{~d})$.

\section{The loading effect}

Consider the effect of a mechanical surface load on the sample of untreated soil compared to the free behaviour of the $2^{\text {nd }}$ wetting of the same unloaded soil sample (a simplified method not used here was proposed by Tariq et al., [26]). In fig. 7a the water intake is somewhat hindered in the wetting phase (left side of fig. 7a) by imposing a $0.596 \mathrm{kPa}$ load. The effect is reversed during the drainage phase of the same sample (right side fig. 7a); this could suggest some reduction of permeability and porosity after loading the soil.

The depression of volume expansion (fig. 7b) is rapid and much more evident (left of 7b) and is kept almost constant in the loading sample even in the draining phase (right of $7 b$ ).

When in addition to the application of the load a lower water pressure $(-18 \mathrm{~cm}$ instead of $+10 \mathrm{~cm})$ is added to the ceramic plate, the reduction of the water intake is much more important (fig. 7c) and even larger is the depression effect on the swelling (fig. 7d). 

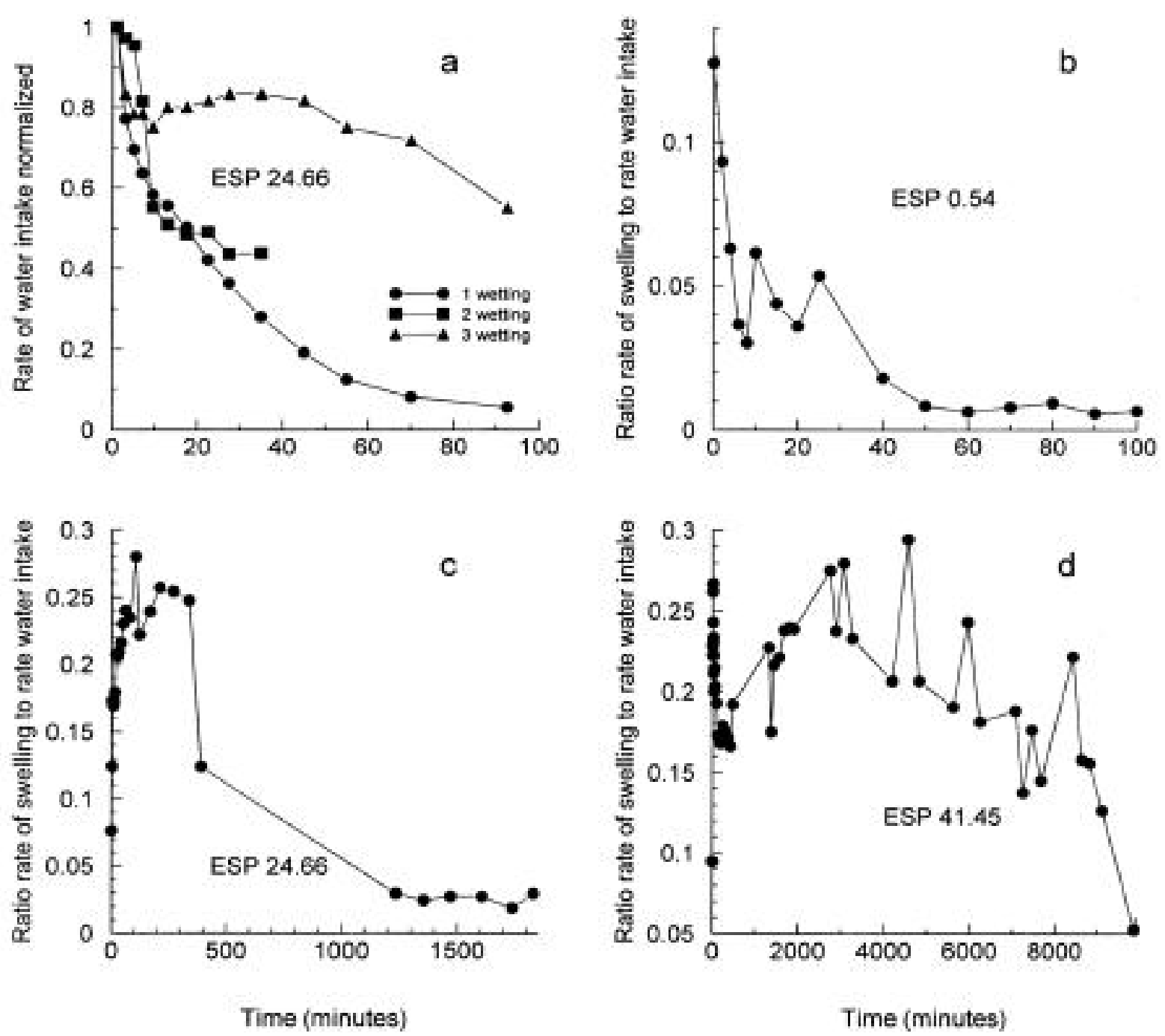

Fig. 5 - a) Change of water intake rate when passing from $1^{\text {st }}$ to $2^{\text {nd }}$ and $3^{\text {rd }}$ wetting; note the delay swelling effect in the $3^{\text {rd }}$ wetting. b-c-d) Ratio between rate of swelling and rate of water intake as a function of ESP. First wetting . Note the strong differences in scale of abscissas.

On the sodicated sample (at 24.66 ESP; fig. 7 e-f) the effect of the combined effect of the mechanical load associated to a lower feeding water pressure (-18 $\mathrm{cm})$ seems to have two kind of effects as indicated by the crossing of the lines in fig. 7e-f: $1^{\text {st }}$ it reduces both the water intake and the swelling to which the sample tend in time, and $2^{\text {nd }}$ it takes much more time to equilibrate (more evident in fig. 7f), suggesting a strong reduction for water permeability.

The few data for this type of tests do not permit to evaluate the coefficients of compressibility [5], especially for the fact that in our case we have to face with the initial primary compression phase. It seems, however, that the effects indicated in fig. 7 are of interest especially when considering the low load applied.

\section{The drain process}

The drainage process poses questions on what kind of relationship exist between the water outflow and the structure of the shrinkage curve possibly articulate

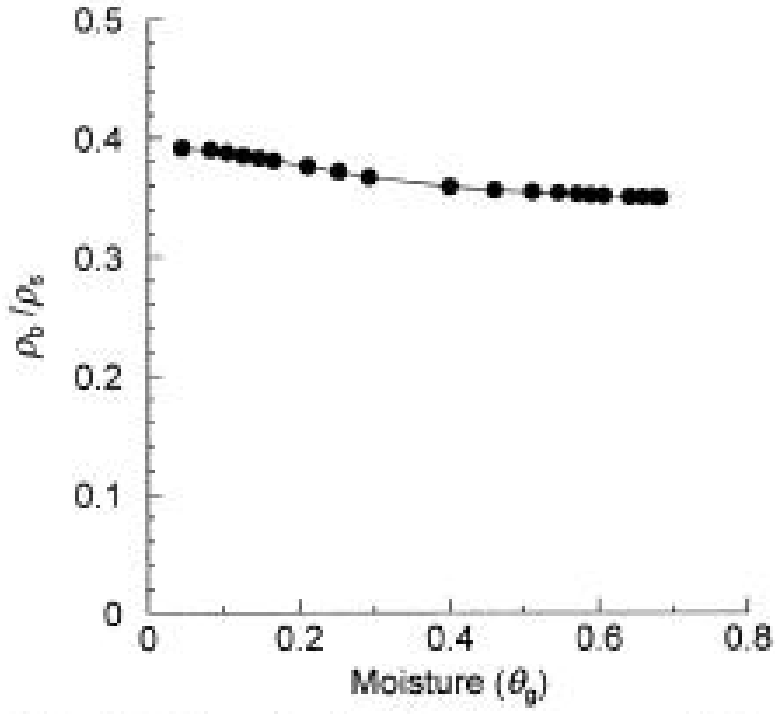

Fig. 6 - Variation as function of mean water content $(\mathrm{kg} / \mathrm{kg})$ of the mean sample parameters; $\rho_{\mathrm{b}} / \rho_{\mathrm{s}}=1 /(1+e)=V_{\text {sol }} / V_{\Sigma}=\theta_{\mathrm{s}}=\mathrm{d} m / \mathrm{d} z$, where $V_{\text {ol }}=$ volume of solids, $V_{\Sigma}=$ total sample volume; $\theta=$ solid content in the sample $\left(V_{\text {sol }} / V_{\Sigma}\right) ; m=$ material coordinate; $z$ eulerian coordinate. 

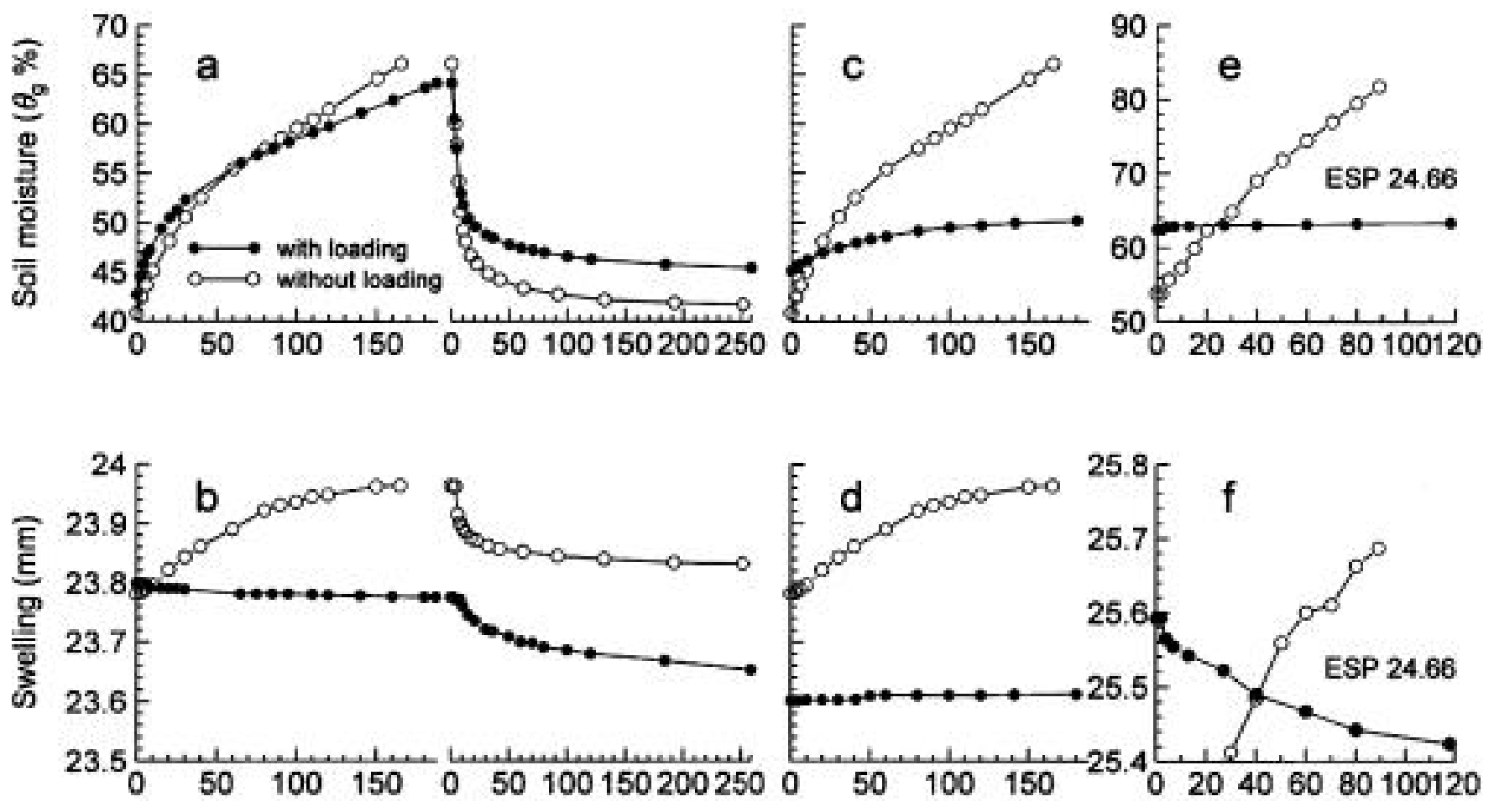

Time (minutes)

Time (minutes)

Fig. 7 - Effect of imposed load $(0.596 \mathrm{kPa})$ on the surface of the soil column with eventual variation of the feeding water pressure at $-18 \mathrm{~cm}$, to the behaviour of moisture $\left(\theta_{\mathrm{g}}\right)$ and soil swelling $(e)$; dark circle $=$ loaded sample; empty circle $=$ unloaded controls. Behaviour and feeding pressure for the controls were taken in the $2^{\text {nd }}$ run of each test.

Wetting (left) followed by draining (right) in untreated soil under load: a) soil moisture; b) soil swelling; c) moisture change in the wetting phase for untreated soil under the surface load and simultaneous reduction of water intake pressure $-18 \mathrm{~cm}$; ) as for c for the swelling; e) as in c for soil sodicated at $24.66 \% \mathrm{ESP} ; \mathrm{f}$ ) as for e referred to soil swelling.

in domains. In these drainage tests the relatively long time of each trial starting from saturated soil suggests that the water in this weak flux is not too far from a condition of equilibrium.

It is striking that in about all cases the draining from an almost saturated sample has a slope of the shrinking function ( $\partial e / \partial \vartheta$; fig. $8 \mathrm{a}-\mathrm{b})$ very low as it could be expected for the structural domain (obviously excluding the residual domain), and not for a basic domain. Only in the case of the outflow from the more sodicated soil (fig. 8c) this slope doubtless deviates along the directrix of the $e-\vartheta$ axes and shows a slope of about 1 which is typical of the basic domain far a paste clay (this agrees to the idea that the clay structure of this sodicated sample is strongly damaged). From those results one should conclude that the tests previously described with the oedotensiometer refers only to a non typical domain of the swelling soils; most typical should be considered what happens in the basic domain as shown by fig. $8 \mathrm{c}$.

This conclusion offers the possibility of concentrating the attention on the analysis of the structural domain for the distribution of pores of which no special requisite are usually demanded, compared to usual distribution in common structured soils at least at these moisture. It seems indeed that the outflow from our samples is analogous to the one-step procedure for determining the water diffusivity inside a soil sample. Of the many techniques available to this purpose the one suggested by Passioura [16] was preferred to those (more numerous) aiming at a parameterization of the diffusivity, because of the theoretically founded basis of the former. This technique neglects gravity for one dimensional flow (along the samples axis) and searches for the determination of the water diffusivity, $D\left(\theta_{\mathrm{v}}\right)$, in the classical equation for rigid soils (Passioura applied it also to a clay loam soil):

$$
\frac{\partial \vartheta_{\mathrm{v}}}{\partial t}=\frac{\partial}{\partial x}\left(D\left(\vartheta_{\mathrm{v}}\right) \frac{\partial \vartheta_{\mathrm{v}}}{\partial x}\right)
$$

where the volumetric water content $\theta_{\mathrm{v}}=\theta_{\mathrm{g}} \rho_{\mathrm{b}} / \rho_{1}$ and the diffusivity $D$ is thought at each time to be a function of the mean moisture content of the samples, (not of the distance along the soil sample except the part near the outflow end of the column). According to this method the outflow must be distinguished in three stages (Fig. 9a) : the $1^{\text {st }}$ one is very irregular and depends on the condition at the outlet (in the case of this experiment it is complicated by the ceramic plate); during the $2^{\text {nd }}$ stage the column behaves as a semi-infinite column and the cumulative outflow is linearly related to $\sqrt{t}$ (as demonstrated by Crank, [9]); at the 

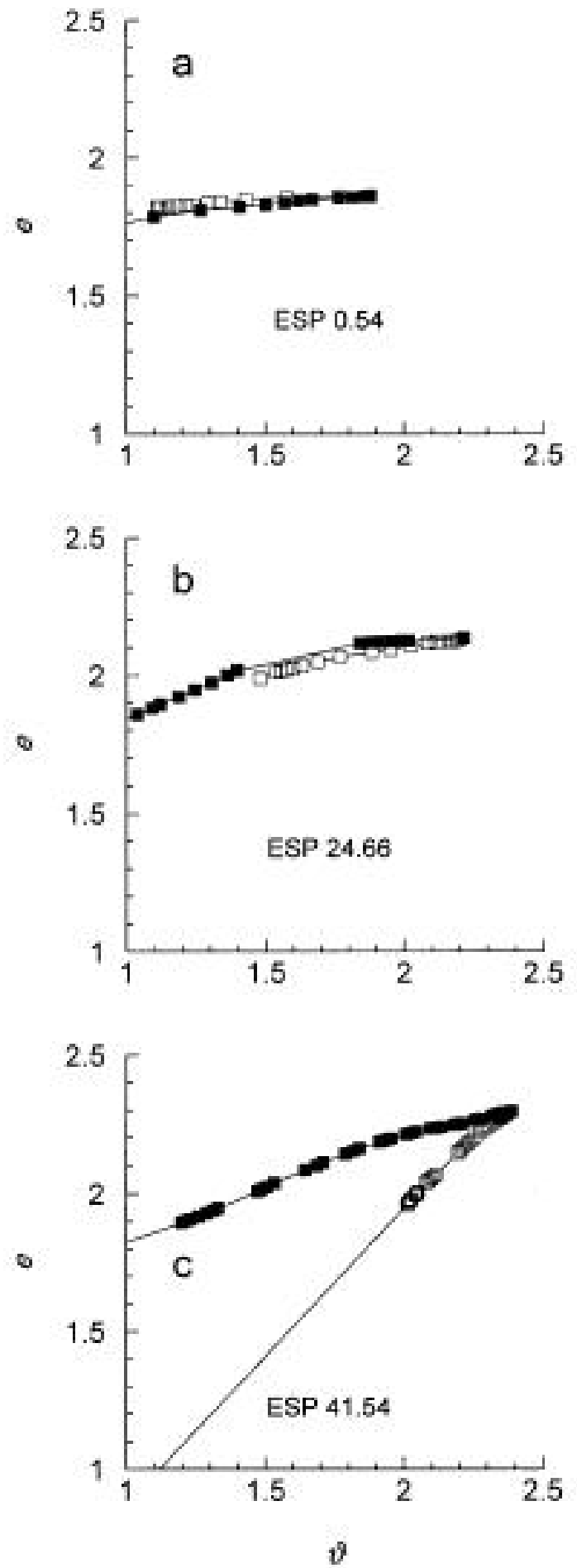

Fig. 8 - Description of curves for wetting (black points; feeding potential $+10 \mathrm{~cm}$ ) and drainage (empty points; suction potential -112 $\mathrm{cm})$ as $e(\vartheta)$ in the soil sample: a) control soil (ESP $0.54 \%$ ); b) sodicated soil at ESP $24.66 \%$ and c) sodicated soil at ESP 41.54. In the last case $\Delta e / \Delta \vartheta \approx 1$ indicate that the soil is in the basic domain.

$3^{\text {rd }}$ stage the cumulative outflow ceases to be linear with respect to $\sqrt{t}$ and this stage is the one which can be used to determine $D$. The development of Passioura [16] brings to the equation:

$$
D\left(\vartheta_{\mathrm{v}}\right)=\frac{\mathrm{d} Q}{\partial \vartheta_{\mathrm{v}}} \cdot \frac{L^{2}}{2}
$$
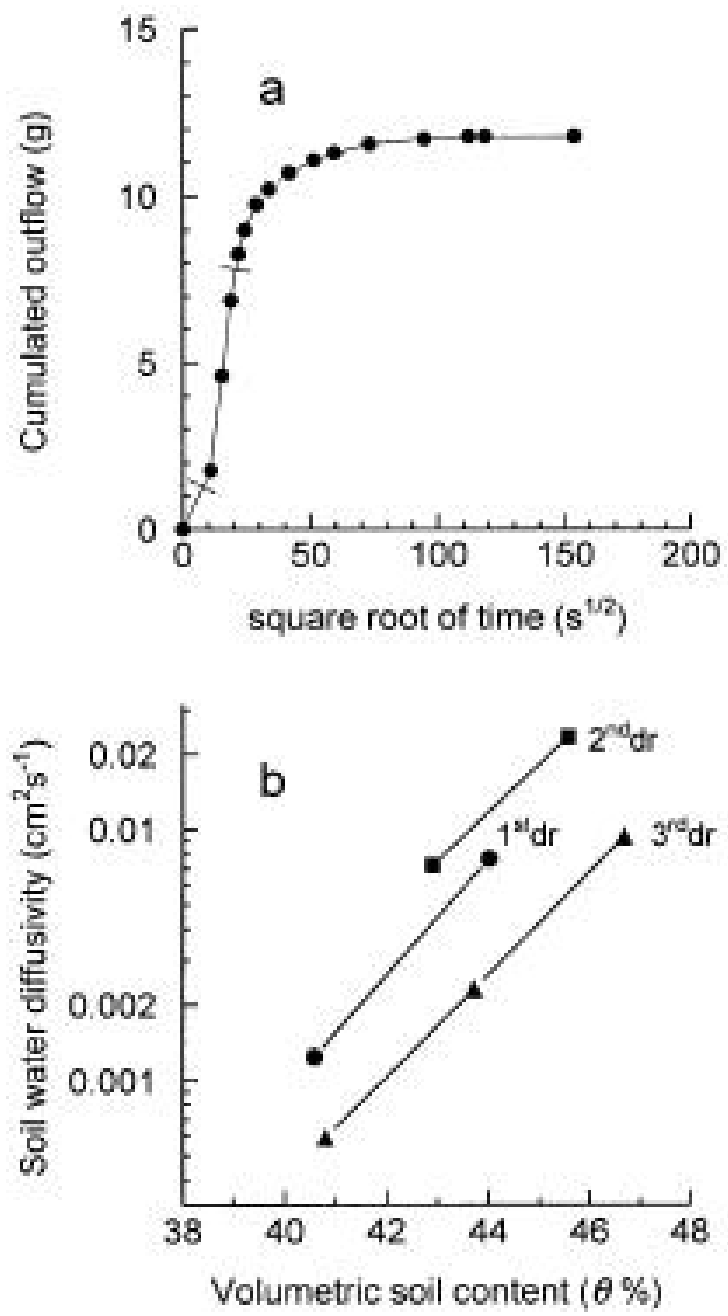

Fig. 9 - a) Example of cumulative outflow (draining) as a function of square root of time for the soil sample showing the three stages: initial (perturbated); linear (theoretically valid for the semi-infinite saturated soil column); deviated due to finite column (useful for diffusivity determinations). b) calculated diffusivity $D$ as function of $\theta_{\mathrm{v}}$, for three untreated soil draining tests.

where $Q=-\partial\left(\theta_{\mathrm{v}}\right) / \partial t$ and $L$ is the sample length. This equation gives $D$ as function of $\bar{\vartheta}_{\mathrm{v}}$; In our case this $\bar{\vartheta}_{\mathrm{v}}$ was easily determined by direct measurement from the oedometric test, so that further calculation given by Passioura could be omitted.

The outflow data of our experiment shows exactly the distinction of the previous three stages; as in the example given in fig. 9a. The problem was discretized using differences instead of differentials and taking $\theta_{\mathrm{g}}(t)$ and $\rho_{\mathrm{b}}$ from the oedometric measurements. The need to use in equation (2) the differential of $Q$ obliged to consider three points in the outflow graphs of fig. 9a. This reduced much of the available points. The results obtained are shown in fig. $9 \mathrm{~b}$.

They show the relevant increase in water diffusivity when the water content increases. The magnitude of $\mathrm{D}$ is rather high as should be expected for the larger pores of the structural domain involved in this range of $\theta_{\mathrm{v}}$. The differences among the three curves are a function of different drain cycles. 


\section{The basic biphasic domain}

Consider now the portion of the draining graph of fig. $8 \mathrm{c}$ which can be taken with a good approximation as a straight line at about $e \approx \vartheta$ for $\vartheta<2.15$. Lower values $e$ or $\vartheta$ are conditions characteristic of basic domain and mean that the soil is in a biphasic stage, i.e. it does not contain air filled pores. Large pores (corresponding to greater $e$ values) are empty and constitute the structural domain which was considered in previous paragraph.

In the basic domain one expects:

$$
\theta_{\mathrm{s}}+\theta_{\mathrm{v}}=1
$$

where $\theta_{\mathrm{s}}=1 /(1+e)$ is the volumetric concentration of the solid phase and $\theta_{\mathrm{v}}$ is the water volumetric content of the sample. Remember that :

$$
\theta_{\mathrm{v}}=\theta_{\mathrm{g}} \rho_{\mathrm{b}} / \rho_{1}
$$

where $\theta_{\mathrm{g}}$ is the gravimetric water content; $\rho_{\mathrm{b}}$ is the bulk density of the solid and $\rho_{1}$ is that of the water (taken $=1$ ). One could check the validity of these relationship using the points in graph $8 \mathrm{c}$. After computing the values for $\theta_{\mathrm{s}}+\theta_{\mathrm{v}}$ one obtains a total of 1.0068 to 1.0062 for the lower points and higher $\vartheta$ values, 1.023 to 1.027 , for the higher points (not well aligned). The small difference to 1 for the lower points is occasional since in the present case soil and not clay paste are dealt with.

The bulk density is given in any case as :

and

$$
\rho_{\mathrm{b}}=\rho_{\mathrm{s}} /(1+e)
$$

$$
1 / \rho_{\mathrm{b}}=V_{\mathrm{s}}
$$

where $V s$ is the specific soil volume (see fig. 2).

The corresponding values for $V_{\mathrm{s}}$ in the upper uncertain part of the curve would be about 1.44 to 1.47 ; for the more valid lower points $V$ s has a more constant mean of about 1.54. If we consider that: $\theta_{\mathrm{g}}=\vartheta$ $\rho_{1} / \rho_{\text {s }}$, we have for the basic domain of this soil the following swelling-shrinking curve :

$$
V_{\mathrm{s}} \approx \theta_{\mathrm{g}}
$$
not far from unity (according to that part of the pattern of fig. $2 b$ corresponding to the basic domain).

For large values of $e<\vartheta$ a condition of structural domain is expected.

Note that since $\theta_{\mathrm{s}}=1 /(1+e)$ we could evaluate term $\theta_{\mathrm{s}}$ as a continuous punctual function of $\vartheta$ content (or $e$ ) of the soil, instead of the $\bar{\theta}_{\mathrm{s}}$ mean value as was the case in previous fig. 6 .

Material coordinates could be applied to solve special problem in this domain.

\section{Conclusions}

A series of trials using an oedotensiometer were performed to examine the behaviour of sieved soil samples taken from the $A p$ horizon of a typic vertisol. Some sample of the same soil were also treated with $\mathrm{Na}-\mathrm{Ca}$ solutions in order to simulate excessive sodication and salinization as occurring after unwise use of brackish water for irrigation.
The samples in the oedometer were fed from beneath with a water at potential of $+10 \mathrm{~cm}$ (exceptionally $-18 \mathrm{~cm}$ ). In some cases a load of about $0.596 \mathrm{kPa}$ (=1 kg weight) was applied on the sample surface. To drain the sample a water head of $-112 \mathrm{~cm}$ of water was mostly applied.

A preliminary presentation of this swelling soil outlined the shrinkage-swelling behaviour expected from this type of experiment and proposed a non traditional descriptive pattern for the water intake in the sample.

The results show the impossibility to apply to this system the hypothesis of simultaneous water and solid movement into the sample and do not allow the application of most theoretical developments dealing with swelling soils. The records of water content (as $\vartheta$ ) and of sample swelling (as $e$ ) refers indeed to transient and not to equilibrium conditions, so that the $e$ values cannot be related to the $\vartheta$ content.

Interesting is the difference in the rate of the water uptake from the rate of soil swelling as evidenced especially in the first wetting phase. The difference extends to successive wettings when the soil was previously sodicated.

The soil swelling continues somewhat even when the entry of the water flux determine waterlogging on the upper surface of the sample. When this swelling ceases the system is in a stationary condition and this gives the possibility to estimate the hydraulic conductivity of the sample.

For all these reasons most of the recorded data refers to the structural domain of the examined sample. This justifies the rather high water conductivity found for the sample at rest and offers the possibility of determining the water diffusion coefficient that can be mainly attributed to the larger pores of the structural domain.

When the more sodicated soils are examined, the dispersion effect on the clay and corresponding reduced mean pores diameter is such a way that a large part of the water content in the sample is scarcely included in structural pores and after a moderate drainage the remaining water is completely embedded in the small pores of the basic domain which behave as biphasic. This basic domain is the more interesting as a swelling material and some considerations applying the material coordinates are possible.

\section{References}

[1] Apostol T.M., Calcolo. Analisi. 1, 367-370 (1983) Boringhieri.

[2] Blake J.R., Hartge K.H., Particle density. In: Klute A. Methods of soil analysis. Part.1, 380-381. (1986), Am. Soc. Agron., Soil Sci. Am.; Madison.

[3] Benciolini G., Guermandi M., SARno G., I suoli delle aziende sperimentali. Regione Emilia-Romagna, Servizio Geologico e sismico dei suoli, (1996), C.E.R.A.S. Bologna, Italy.

[4] Boivin P., Garnier P., Vauclin M., Modelling the 
soil shrinkage and water retention curves with the same equations. Soil Sci. Soc. Am. J. (2006) 70, 1082-1093.

[5] Bradford J.M., GuPta S.C., Compressibility. In Klute A. Methods of soil analysis. Part 1. Physical and mineralogical methods. $2^{\text {nd }}$ edit., 479-499. Agronomy series (2002) Am. Soc. Agron. A. Soil Sci. Soc. Inc., Madison.

[6] Braudeau E., Mohtar R.H., Modelling the swelling curve for packed soil aggregates using the pedostructure concept. Soil Sci. Soc. Am. J. (2006) 70, 494-502.

[7] Cavazza L., Guarnieri A., Patruno A., Lorenzini G., Cirillo E., Edotensiometro da laboratorio. Riv. Ing. Agr. (2005) 4, 57-63.

[8] Cavazza L., Guarnieri A., Patruno A., Cirillo E., Il comportamento dei suoli agrari rigonfiabili. J. Of Ag. Eng. - Riv di Ing. Agr. (2007) 4, 45-54.

[9] Crank J., The mathematics of diffusion. (1956) Oxford Univ. Press. (cited by Passioura).

[10] Garnier P., Rieu M., Boivin P., Vauclin M., Baveye P., Determining the hydraulic properties of a swelling soil from a transient evaporation experiment. Soil Sci. Soc. Am. J. (1997) 61, 1555-1563.

[11] Groenevelt P.H., Bolt G.H., Water retention in soil. Soil Sci. (1972) 113, 238-245.

[12] Heiskanen J., Comparison of three methods for determining the particle density of soil with liquid pycnometer. Commun. Soil Sci. Plant Anal., (1992) 23, 841-846.

[13] Martignani F., Fluidodinamica del rigonfiamento dei suoli. L'effetto della sodicizzazione. Tesi di laurea, 2003-2004. Ingegneria gestionale, energia. Relatore G. Lorenzini.

[14] McGarry D.M., Malafant K.W.J., The analysis of volume change in unconfined units of soil. Soil Sci. Soc. Am. J. (1987) 51, 290, 297.

[15] Mitchell A.R., van Genuchten Th., Shrinkage of bare and cultivated soil. Soil Sci. Soc. Am. J. (1992) 56, 1036-1042.

[16] Passioura J.B., Determining soil water diffusivity from one- step outflow experiments. Austr. J. Soil Res. (1976) 15, 1-8.

[17] Patruno A., Cavazza L., Cirillo E., Experiments on soil sodication. Italian J. of Agronomy (2003) 6, 3-13.

[18] PhILIP J.R., Hydrostatics and hydrodynamics in swelling soils. Water Resour. Res. (1969) 5, 10701077.

[19] PHILIP J.R., Hydrology of swelling soils. In: Talsma T., Philip J.R. Salinity and water use. (1971), Mc Millan Press.

[20] RaAts P.A.C., Klute A., Transport in Soils. Soil Sci. Soc. Am. Proc. (1968a) 32, 161-166.

[21] RaAts P.A.C., Klute A., Transport in Soils. Soil Sci. Soc. Am. Proc. (1968b) 32, 452-456.

[22] RaAts P.A.C., Klute A., One dimensional simulations motion of the aqueous phase and the solid phase of unsaturated and partially saturated porous media. Soil Sci. (1968) 107, 329-333.

[23] Sposito G., Volume changes in swelling soils. Soil Sci. (1973) 115, 315-320.

[24] Sposito G., Giraldez J.V., Reginato R.J., The theoretical interpretation of field observations of soil swelling through a material coordinate transformation. Soil Sci., Soc. Am. J. (1976) 40, 208-211.

[25] STIRK G.B., Some aspects of soil shrinkage. The ef- fect of cracking upon water entry into the soil. Austr. J. Agric. Res. (1954) 5, 279-290.

[26] TARIQ A.R., DURNFord D.S., TARIQ A., Moisture retention of a swelling soil under capillary and overburden pressure. J. Hydrology (1997) 203, 1-4; 117 128.

[27] UsDA-NRCS. Soil Taxonomy, a basic system of soil classification for making and interpreting soil surveys. $2^{\text {nd }}$ ed. (1999). Agriculture handbook $\mathrm{N}^{\circ} 436$, Washington D.C., 869.

\section{SUMMARY}

An oedotensiometer was used to examine to examine the behaviour of sieved sample of a swelling soil (a vertisol) as well as of the same soils treated with solution of $\mathrm{Na}^{+}+\mathrm{Ca}^{2+}$ to simulate the soil changes from excessive irrigation with brackish water.

The oedometer test consisted in an infiltration of water from below through a ceramic porous plate at a feeding pressure of $+10 \mathrm{~cm}$ water and successive drainage under a depression mostly of $-112 \mathrm{~cm}$ of water.

The rate of water entry as well as the swelling rate of the sample were monitored.

Preliminary considerations regards the domains in which the shrinkage curve of a swelling soil is subdivided and make hypothesis on the swelling process expected when the infiltration from below of the sample is applied.

The results support the hypothesis that when the water pressure is applied some water enters rather rapidly in the larger structural pores and is followed later by the swelling in the smaller pores, responsible for the basic domain. This first conclusion demonstrates that the assumption of a simultaneous movement of solid and liquid components in the sample, which is the base of most theoretical developments for swelling soils, cannot be accepted for the tested samples.

Some cases with water clogging on the sample surface confirm a late final swelling of the soil and permitted to evaluate the hydraulic conductivity of the swollen soil.

These manifestations are more evident in sodicated soils. The loading of the sample reduces the swelling of the sample and seems to reduce its permeability. The reduction of the feeding water pressure further reduces the sample swelling.

The draining process from saturated soil sample shows that most of the process occurs in the large pores of the structural domain. This gives the possibility to evaluate the water diffusivity coefficient for the structural domain of the sample.

In draining the soil with the highest sodication there was a variation of soil volume practically equal to the water lost, demonstrating that in this case the shrinking state of the soil was in the basic domain and the soil was in a biphasic condition (no air phase in the wetted soil part). This was the only case in which material coordinate arguments could be applied and the soil completely obeys to swelling properties in quasi equilibrium conditions. 
Key words:

Oedotensiometer tests; non simultaneous water and solid flow; structural porosity diffusivity; $K_{\mathrm{s}}$ in oedotensiometer; sodication effects; load and water tension effects.

Appendix. Calculation of the saturated water conductivity $\left(K_{\mathrm{s}}\right)$ during water accumulation on the oedotensiometer soil sample.

\section{From Darcy's law:}

$$
q=-K, \frac{\Delta \psi}{\Delta z}
$$

however $q=\frac{\mathrm{d} h}{\mathrm{~d} t}$ is the water flux density in upward direction (opposite to the usual presentation); $h$ is the height of the water on the sample; then its accumulation in time $(t)$ is a measure of $q ; K_{\mathrm{s}}$ is the saturated water conductivity; $z$ is the length of the porous material (from top to base); $\Delta \psi$ is the difference in positive potential head $(\Delta \psi / \Delta z<0)$;

For the ceramic plate (saturated; subscr.: cer.):

$$
q=-K_{\mathrm{cer}} \frac{\Delta \psi_{\mathrm{cet}}}{\Delta z_{\mathrm{ctr}}}
$$

where $\Delta \phi_{\text {cer }}$ is the head loss due to the resistance of the ceramic plate and is a function of $q$ the flux intensity directed upward.

Furthermore $q=\frac{\mathrm{d} h}{\mathrm{~d} t}=-L_{\text {peer }} \Delta \psi_{\mathrm{cer}}$ and $L_{\mathrm{pser}}=\frac{K_{\mathrm{ctr}}}{\Delta z_{\mathrm{cer}}}$ is the water conductance of the ceramic plate per unit area of the plate; and then $\psi_{\mathrm{or}}=-\frac{\mathrm{d} h}{\mathrm{~d} t} \frac{1}{L_{\text {por }}}$ (to be subtracted from the feeding pressure of $+0.1 \mathrm{~m}$ ).

For the whole system (fig. 10) during the water accumulation the water flows upward in response to the negative total potential $\left(\psi_{\Sigma}\right)$ with gradient $\left(\Delta \psi_{\Sigma} / \Delta z\right)$ from the ceramic bottom (where $\psi=+0.1 \mathrm{~m}$ ) to the upper level (where $\psi=0$; atmospheric pressure).

In the different sections of the water path of this system the flux is stationary for each instantaneous condition. Therefore $\partial h / \partial t$ is instantaneously equal for all sections and the use of $\partial$ instead of $d$ is only to indicate that $h$ varies in time and tends to $h_{\mathrm{M}}$ (the maximun depth of water on the soil).

If one considers the soil sample section only, one has from (1):

$$
\frac{\partial h}{\partial t}=-K, \frac{\Delta y}{S}
$$

where $S$ is the soil sample length measured from the bottom to the top and is therefore negative; it is referred to the maximum water level in the system; the other symbols as said. In the equation (3) the reduction of the potential pressure when passing along the

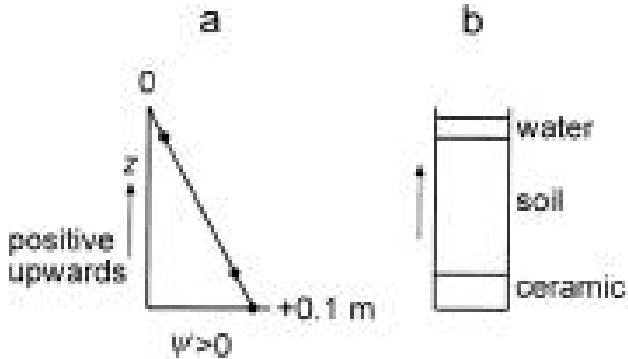

Fig. 10- a) Graph of the reduction of water pressure along the upward path; b) graph of the water path during water accumulation.

water flux from the base of the soil sample to the top (an inverse direction compared to the usual one) implies that the water path in the sample is $-S$. The two end potentials are $\left[0.1-(\mathrm{d} h / \mathrm{d} t) / L_{\text {pcer }}\right]$ and $h$ respectively at the bottom and on the top. We can invert the signs for the potential so the equation (3) becomes:

$$
\frac{\partial h}{\partial t}=\frac{-K_{\mathrm{x}}}{-S}\left[-h+\left(0.1-\frac{\partial h 1}{\partial t L_{\text {por }}}\right)\right]
$$

Note that at the end of the accumulation process according to this equation $-h$ tends to $-h_{\mathrm{M}}$.

One can easily find the following transformation of (4):

$$
\frac{\partial h}{\partial t}=(0.1-h)\left(\frac{1}{L_{\text {per }}}+\frac{S}{K_{x}}\right)^{-1}
$$

On the other side one can take:

$$
\frac{\partial h}{\partial t}=\frac{-\partial(0.1-h)}{\partial t}
$$

because in this problem +0.1 is a constant and only $h$ is a time variable. Therefore from (5) and (6) after separating the variables one finds:

$$
\begin{aligned}
& \frac{\partial(0.1-h)}{0.1-h}=-\left(\frac{1}{L_{\text {pos }}}+\frac{S}{K_{s}}\right)^{-1} \mathrm{~d} t \\
& \ln (0.1-h)=-\left(\frac{1}{L_{\text {pore }}}+\frac{S}{K_{\mathrm{s}}}\right)^{-1} \mathrm{~d} t
\end{aligned}
$$

At this point remember that according to the (4) the absolute value of $-h$ tends to increase up to $-h_{\mathrm{M}}$ which gives the possibility to integrate the members of the (8); otherwise ( $h-0.1)$ would be negative. From this is obtained:

$$
\int_{-h_{M}}^{0} \ln (01-h) \mathrm{d} h=-\left(\frac{1}{L_{\text {Deer }}}+\frac{S}{K_{s}}\right)^{-1} \int_{t_{0}}^{t=e n d} \mathrm{~d} t
$$

The advantage of the inversion of signs in equation 4 gives in equation 9 the possibility of having a positive value for the argument for the logarithm. The solution for the definite integral of the left member of the (9) can be indicated as a symbol [I]. Then 
$(0.1 \times \ln 0.1)-\left(0.1-h_{\mathrm{M}}\right)\left[\ln \left(0.1-h_{\mathrm{M}}\right)\right]-h_{\mathrm{M}}=[\mathrm{I}]$

Note that this whole integral expands in the negative values of $h$ (from $-h_{\mathrm{M}}$ to 0 ) and one should expect to have $[\mathrm{I}]$ negative, notwithstanding the fact that it means a positive water accumulation (this is due to the signs inversion in equation (4)). So, according to equation (9) and (10) one has:

$$
[\mathrm{I}]=\frac{\Delta t}{-\left(\frac{\mathrm{I}}{L_{\mathrm{par}}}+\frac{S}{K_{\mathrm{s}}}\right)}
$$

where $\Delta t$ is the total time required for the water accumulation $\left(t_{\text {end }}-t_{0}\right)$.

From which:

$$
K_{,}=\frac{-S}{\frac{1}{L_{\text {per }}}+\frac{\Delta t}{[I]}}
$$

In numerical values (data from tab. 4) :

$[\mathrm{I}]=(0.1 \times \ln 0.1)-\left[\left(0.1-2.193 \times 10^{-3}\right) \times \ln (0.1-\right.$ $\left.\left.2.193 \times 10^{-3}\right)\right]-2.193 \times 10^{-3}=-5.0653 \times 10^{-3}$ and

$$
K_{n}=\frac{-24.13 \times 10^{-3}}{\frac{1}{1.23 \times 10^{-4}}-\frac{3780}{5.0653 \times 10^{-3}}}-+3.269 \times 10^{-8} \mathrm{~m} \mathrm{~s}^{-1}
$$

The Authors are indebted to Prof. G. Vitali for suggestions on the integral formula 
003_Cavazza(512)_11 13-02-2009 12:58 Pagina 26

$\phi$ 